\title{
FORÇA DE TRAÇÃO NECESSÁRIA EM FUNÇ̃̃O DO NÚMERO DE LINHAS DE SEMEADURA UTILIZADAS POR UMA SEMEADORA-ADUBADORA DE PRECISÃO ${ }^{1}$
}

\author{
ALCIR J. MODOLO ${ }^{2}$, ANTONIO GABRIEL FILHO ${ }^{3}$, SUEDÊMIO DE L. SILVA ${ }^{3}$, \\ ESTOR GNOATTO ${ }^{4}$
}

\begin{abstract}
RESUMO: Este trabalho teve como objetivo avaliar o comportamento da força de tração solicitada por uma semeadora-adubadora, variando o número de linhas de semeadura. O experimento foi conduzido no Núcleo Experimental de Engenharia Agrícola - NEEA, pertencente à UNIOESTE Câmpus de Cascavel - PR, em um Latossolo Vermelho distroférico com relevo plano e textura argilosa. Utilizou-se o delineamento experimental de blocos ao acaso, composto por cinco tratamentos e quatro repetições. Foram utilizados os seguintes tratamentos: semeadora equipada com uma, duas, três, quatro e cinco linhas de semeadura, deslocada à velocidade média de $5,5 \mathrm{~km} \mathrm{~h}^{-1}$. Avaliaram-se os parâmetros de profundidade do sulco, área de solo mobilizada, força de tração média e força de tração máxima. Com o aumento do número de linhas de semeadura de uma para cinco, a força de tração média na barra aumentou de 3,7 para $8,6 \mathrm{kN}$, ou seja, houve acréscimo de 131,9\%.
\end{abstract}

PALAVRAS-CHAVE: semeadora-adubadora, força de tração, profundidade do sulco.

\section{TRACTION FORCE NECESSARY IN FUNCTION OF THE NUMBER OF SOWING LINES USED BY A SEED-DRILL}

\begin{abstract}
This work aimed to evaluate the behavior of the traction force requested by a seederdrill varying the number of lines of sowing. The experiment was leaded in the Experimental Nucleus of Agricultural Engineering - NEEA, belonging to the UNIOESTE - Campus of Cascavel, Paraná, Brazil, in Red Latosoil Haplortox with plane relief and loamy texture. The experimental design used was of blocks by chance with five treatments and four repetitions. It was used the following treatments: seeder equipped with one, two, three, four and five sowing lines, which were moved in an average speed of $5.5 \mathrm{~km} \mathrm{~h}^{-1}$. The parameters evaluated were: depth of the furrow, soil area mobilized, average traction force and maximum traction force. With the increase of the number of sowing lines of one for five, the average traction force in the bar increased from 3.7 to $8.6 \mathrm{kN}$, in other words, there was an increment of $131.9 \%$.
\end{abstract}

KEYWORDS: seeder-drill, traction force, depth of the furrow.

\section{INTRODUÇÃO}

O processo produtivo agrícola, fundamentado na produção de grãos por meio de sistemas sustentáveis, com o uso de práticas conservacionistas adequadas, exige o desenvolvimento de máquinas e equipamentos agrícolas cada vez mais eficientes e precisos. Nesse contexto, estão enquadradas as semeadoras, que passaram a assumir importância fundamental nesse moderno sistema de produção. OLIVEIRA et al. (2000) relatam que houve grande evolução das semeadoras-adubadoras utilizadas nesse sistema, principalmente quanto à sua concepção e utilização, sendo que as principais

\footnotetext{
${ }^{1}$ Extraído da dissertação de mestrado do primeiro autor.

${ }^{2}$ Mestre em Engenharia Agrícola, Rua Academia 1.202, Jardim Universitário, Cascavel - PR, Fone: (0XX45) 324-7296, alcir@vicosa.ufv.br

${ }^{3}$ Prof. Adjunto, Departamento de Engenharia Agrícola, UNIOESTE, Cascavel - PR.

${ }^{4}$ Mestrando em Engenharia Agrícola e professor do CEFET - Medianeira - PR.

Recebido pelo Conselho Editorial em: 11-8-2003

Aprovado pelo Conselho Editorial em: 10-8-2005
} 
mudanças ocorreram nos mecanismos de distribuição de fertilizantes, os quais eram constituídos basicamente por discos duplos, atualmente substituídos por hastes rompedoras.

Existem diversos tipos e combinações de sulcadores para sementes e adubos em função do preparo de solo realizado, tipo, quantidade e forma de disposição dos resíduos ou de plantas de cobertura, tipo de solo, teor de água, grau de compactação da camada superficial, profundidade de semeadura, velocidade e grau de mobilização do leito de semeadura desejado (ASAE, 1996). No Brasil, as opções mais empregadas são os sulcadores de disco triplo, discos duplos de mesmo diâmetro, discos duplos de diâmetros diferentes (defasados) e os do tipo haste.

A melhor haste é aquela que consegue penetrar com facilidade no solo mais endurecido superficialmente, típico do sistema plantio direto, exigindo baixa força de tração e movimentando pouco solo no sulco (ARAÚJO et al., 2001). Segundo o mesmo autor, o desempenho da haste depende de vários fatores, tais como, velocidade de operação, posição em relação aos demais sulcadores da semeadora, condições de solo (densidade, teor de água e resistência à penetração), nível de aderência de solo e das características geométricas da própria haste.

ARAÚJO et al. (1998) identificaram que, na região oeste do Estado do Paraná, a compactação superficial dos solos constitui forte restrição para a semeadura direta, onde o uso de sulcadores do tipo haste ou facão tem se generalizado como alternativa para rompê-la. Essas hastes exigem maior esforço de tração e maior consumo de combustível quando comparado ao mecanismo sulcador de discos duplos.

As necessidades de tração dos implementos agrícolas são dependentes de variáveis como o solo, o próprio implemento e outras. Dentro da variável solo, destacam-se: a distribuição do tamanho dos agregados, a textura, o teor de água, a densidade do solo, a estrutura, os efeitos da declividade, da vegetação e dos resíduos de culturas anteriores. O implemento pode influir no esforço de tração, conforme o tipo de ferramenta usada, as características do metal que está em contato com o solo, a superfície em contato com o solo, a curvatura, a forma e as condições da superfície da ferramenta onde a força é aplicada. Outras variáveis incluem largura e profundidade do sulco e velocidade de deslocamento da máquina (TELISCHI et al., 1979, citados por FAGANELO, 1989).

A força de tração necessária para a operação de semeadoras de grãos graúdos (semeadora de precisão), na direção horizontal do deslocamento, já incluída a resistência ao rolamento da máquina, com bom leito de semeadura, varia de $900 \mathrm{~N} \pm 25 \%$ por linha (somente semeadura) e de $3.400 \mathrm{~N}$ $\pm 35 \%$ por linha (semeadura, adubação e herbicida) (ASAE, 1999).

A transferência de força vertical ao rompedor de solo e o controle da profundidade de semeadura são aspectos que estão intimamente correlacionados aos mecanismos atuais (molas helicoidais de tração ou compressão e limitadores) das semeadoras para plantio direto. Com esses mecanismos, uma eficiente transferência de carga aos rompedores de solo e um adequado controle de profundidade de semeadura não são alcançados, pois sua regulagem é manual, permanecendo constante no decorrer do trabalho, sendo necessário acompanhamento contínuo do operador para verificar se a condição de semeadura estabelecida está sendo atendida (MORRISON JUNIOR, 1988).

O presente trabalho tem por objetivo avaliar a força de tração solicitada por uma semeadoraadubadora de precisão com diferentes números de unidades de semeadura. Especificamente, buscou-se determinar as constantes das molas dos mecanismos sulcadores e recobridores de sementes para que as pressões exercidas pelas mesmas fossem iguais em todas as linhas de semeadura, bem como avaliar a profundidade do sulco e a área de solo mobilizada. 


\section{MATERIAL E MÉTODOS}

O experimento foi desenvolvido no Núcleo Experimental de Engenharia Agrícola - NEEA, pertencente à Universidade Estadual do Oeste do Paraná - Câmpus de Cascavel - PR, em solo classificado pela EMBRAPA (1999), como sendo Latossolo Vermelho distroférico, com relevo plano e textura argilosa. Utilizou-se do delineamento experimental de blocos ao acaso, composto por cinco tratamentos e quatro repetições. A área foi subdividida em quatro blocos casualizados, totalizando 20 parcelas experimentais, cada uma com área de 59,5 $\mathrm{m}^{2}$ (3,5 x $\left.17 \mathrm{~m}\right)$, com espaçamento entre parcelas de $10 \mathrm{~m}$, utilizados para manobra e estabilização do conjunto motomecanizado. Os cinco tratamentos foram compostos por uma, duas, três, quatro e cinco linhas de semeadura, doravante denominados T1, T2, T3, T4 e T5, respectivamente, deslocados à velocidade média de 5,5 $\mathrm{km} \mathrm{h}^{-1}$.

No tratamento T1, utilizou-se somente da linha central na configuração da máquina. Já os tratamentos T3 e T5 foram compostos por mais uma e duas linhas em cada lado da linha central, respectivamente, enquanto nos tratamentos T2 e T4 não se utilizou da linha central, conforme apresentado na Figura 1.

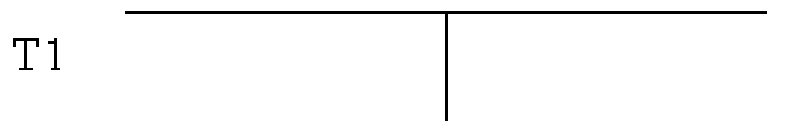

L.2
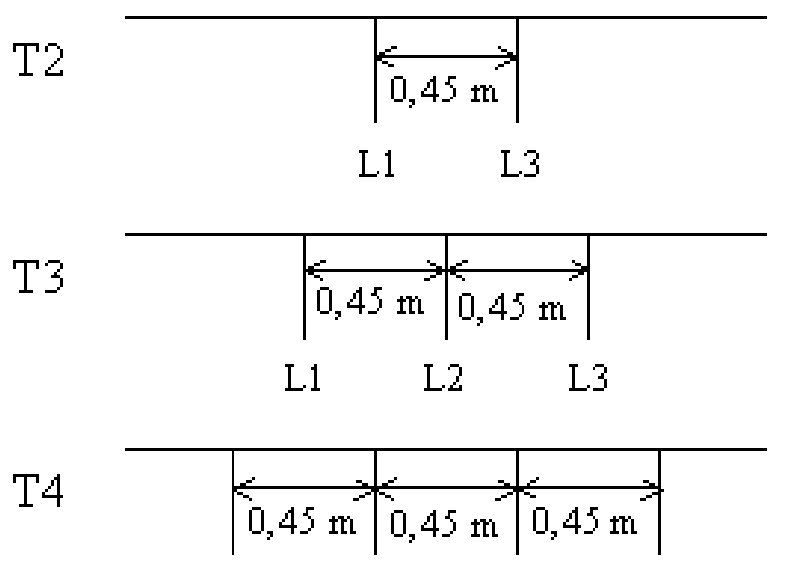

L4 L.1 L3 L5

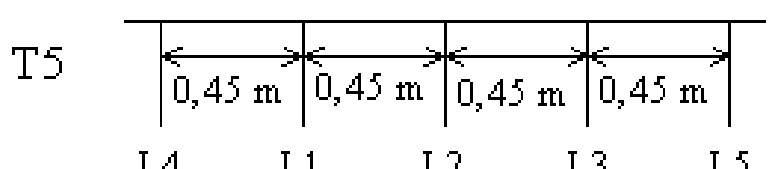

FIGURA 1. Disposição das linhas de semeadura nos diferentes tratamentos.

Utilizou-se de trator marca FORD, modelo 7630 4x2 com tração dianteira auxiliar (TDA), potência de 75,8 kW (103 cv) e uma semeadora-adubadora de precisão marca Vence Tudo, modelo SMT 6414 de arrasto, com mecanismos sulcadores do tipo haste sulcadora para fertilizantes e discos duplos defasados para sementes.

A umidade do solo na semeadura foi determinada utilizando-se do método gravimétrico padrão, conforme (EMBRAPA, 1997).

$\mathrm{Na}$ determinação das constantes das molas, conforme Figura 2, utilizou-se de célula de carga marca Transtec com capacidade para $500 \mathrm{~kg}$, para monitorar a carga aplicada. Para medir o deslocamento " $\mathrm{X}$ " da mola, utilizou-se de roldana com diâmetro conhecido fixada na extremidade do 
eixo do potenciômetro multivoltas (10 voltas) de $20 \mathrm{~K} \Omega$, modelo 7221 da Beckman Instruments. Os valores gerados pelos transdutores foram coletados e armazenados no sistema de aquisição de dados computadorizado "micrologger 23X". Os dados foram posteriormente transferidos para um computador e processados.

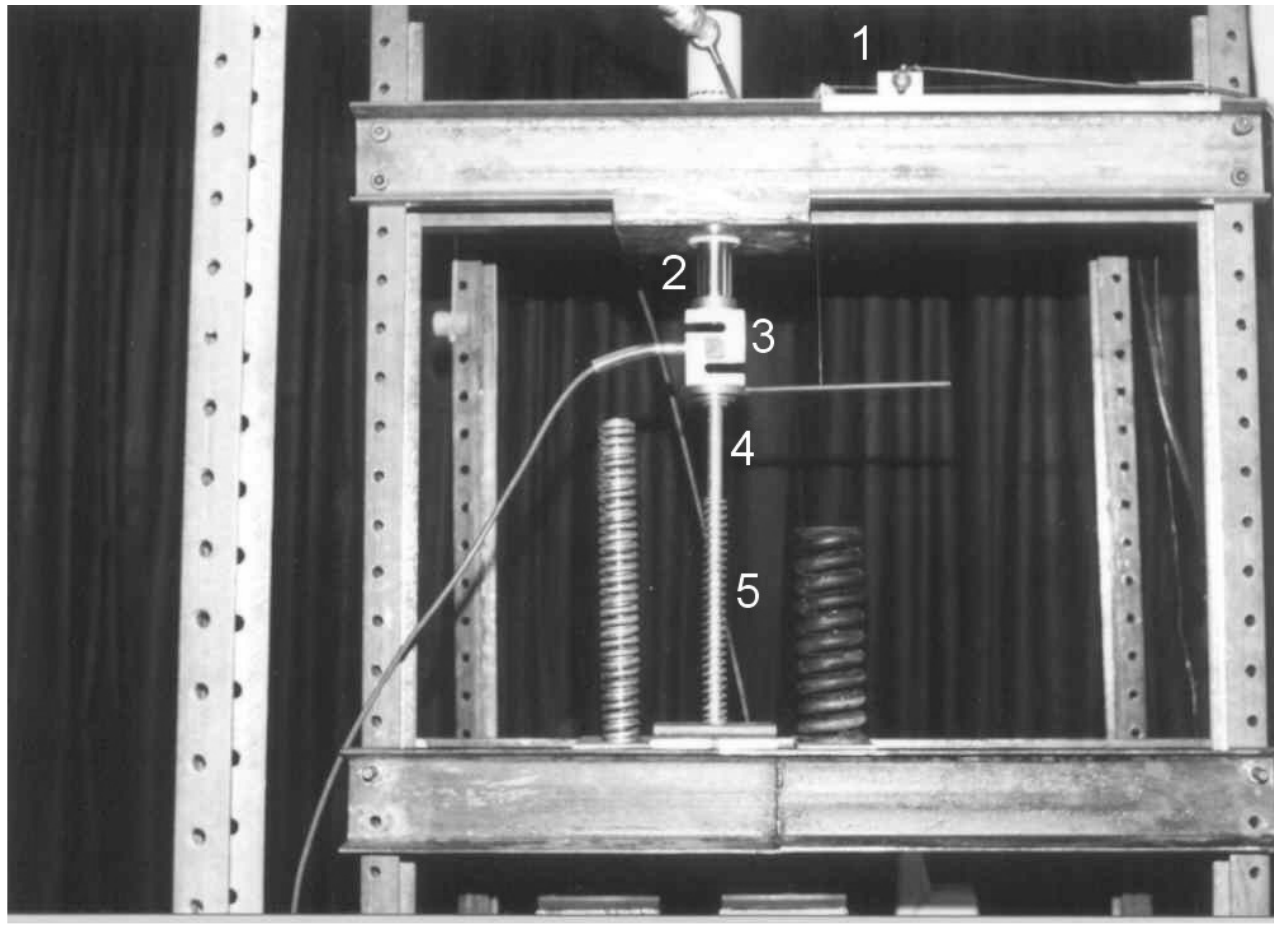

FIGURA 2. Vista geral dos equipamentos utilizados no ensaio das constantes das molas: (1) potenciômetro (2) pistão hidráulico (3) célula de carga (4) haste-guia e (5) mola.

A constante das molas foi determinada com auxílio da eq.(1). A haste-guia foi utilizada com a finalidade de evitar a flambagem na mola quando a carga fosse aplicada. À medida que a carga era aplicada sobre a mola, a roldana era acionada por meio de um cordão de náilon fixado na haste guia, gerando um sinal analógico de tensão proporcional ao deslocamento da mola.

$$
\mathrm{F}=\mathrm{kX}
$$

em que,

$\mathrm{F}$ - força aplicada na mola, $\mathrm{N}$;

$\mathrm{k}$ - constante da mola, e

$\mathrm{X}$ - deformação da mola, cm.

Para que a pressão exercida pelas molas nos mecanismos sulcadores fosse igual em todas as linhas de semeadura, a regulagem da semeadora foi realizada de acordo com os valores obtidos para as constantes de cada mola, seguindo e eq.(1):

Para determinar a força horizontal na barra de tração necessária para tracionar a semeadora, utilizou-se de célula de carga marca SODMEX, modelo N400, com sensibilidade de 2,16 mV/V e escala nominal de $50 \mathrm{kN}$, inserida entre o trator e a semeadora. $\mathrm{O}$ pino que prende a barra foi retirado de modo que a barra ficasse livre e toda a força de tração solicitada pela semeadora fosse aplicada à célula de carga. A força de tração média foi determinada por meio da eq.(2): 


$$
F_{m}=\frac{\sum_{i=1}^{n} F i}{n}
$$

em que,

$\mathrm{F}_{\mathrm{m}}$ - força de tração média, $\mathrm{N}$;

$F_{i}$ - força de tração instantânea, N, e

n - número de dados registrados.

Para gravar e armazenar os sinais gerados pelos transdutores instalados no trator, utilizou-se de sistema de aquisição de dados computadorizado "micrologger" da CAMPBELL SCIENTIFIC, modelo CR23X.

Para o levantamento do perfil de solo mobilizado, foi utilizado um perfilômetro, construído em alumínio, com réguas verticais graduadas em centímetros, dispostas a cada $2 \mathrm{~cm}$ no sentido transversal, sendo realizado em todas as linhas de semeadura o levantamento de três perfis: perfil da superfície natural do solo; perfil da superfície final do solo, e perfil interno do solo mobilizado. $\mathrm{O}$ cálculo da área mobilizada pode ser feito por meio de planimetria ou pela eq.(3):

$$
\mathrm{Am}=\sum\left(\mathrm{P}_{\mathrm{N}}-\mathrm{P}_{\mathrm{F}}\right) \mathrm{e}
$$

em que,

Am - área mobilizada, $\mathrm{cm}^{2}$;

$\mathrm{P}_{\mathrm{N}}$ - valor do perfil da superfície natural do solo para cada ponto do perfilômetro, $\mathrm{cm}$;

$\mathrm{P}_{\mathrm{F}}$ - valor do perfil da superfície final do solo para cada ponto do perfilômetro, $\mathrm{cm}, \mathrm{e}$

e - espaçamento entre réguas verticais, $\mathrm{cm}$.

A profundidade do sulco foi determinada em todas as linhas de semeadura, sendo realizadas cinco repetições por linha.

\section{RESULTADOS E DISCUSSÃO}

Todos os parâmetros e análises estatísticas referentes aos dados obtidos no experimento, bem como os valores calculados a partir desses, serão apresentados na forma de Tabelas, em que as médias seguidas de mesmas letras maiúsculas nas colunas não diferem estatisticamente entre si, pelo teste de Tukey, a 5\% de probabilidade.

Os resultados obtidos para o teor de água do solo na profundidade de 0 a $10 \mathrm{~cm}$, em amostragem realizada no dia do ensaio, são apresentados na Tabela 1.

TABELA 1. Valores médios do teor de água no solo $\left(\mathrm{kg} \mathrm{kg}^{-1}\right)$ na profundidade de $0 \mathrm{a} 10 \mathrm{~cm}$.

\begin{tabular}{cc}
\hline Tratamentos & $\begin{array}{c}\text { Teor de Água } \\
\left(\mathrm{kg} \mathrm{kg}^{-1}\right)\end{array}$ \\
\hline T1 & 25,35 \\
T2 & 25,68 \\
T3 & 25,87 \\
T4 & 27,74 \\
T5 & 25,97 \\
\hline
\end{tabular}




\section{Avaliação das molas dos mecanismos sulcadores (adubo e semente) e recobridores de sementes}

Na Tabela 2, são apresentados os valores do comprimento, diâmetro e constante das molas dos mecanismos: sulcadores de adubo (MSA), sulcadores de sementes (MSS) e recobridores de sementes (MRS), na qual se observa que todas as molas ensaiadas apresentaram diferenças quanto ao comprimento, diâmetro e constantes. Verifica-se, também, que a amplitude de variação do comprimento das molas foi de 1,0 cm nos MSA, 0,4 cm nos MSS e 2,2 cm nos MRS. A amplitude de variação do diâmetro das molas foi de 0,04 cm nos MSA, 0,06 cm nos MSS e 0,03 cm nos MRS. Levando em consideração que a semeadora é praticamente nova e tem poucas horas de trabalho, essa variação do comprimento e diâmetro das molas não pode ser atribuído a desgaste das mesmas.

TABELA 2. Valores do comprimento, diâmetro e constante das molas dos mecanismos sulcadores: adubo (MSA), sementes (MSS) e recobridores de sementes (MRS).

\begin{tabular}{|c|c|c|c|}
\hline Descrição & Comprimento $(\mathrm{cm})$ & Diâmetro $(\mathrm{cm})$ & Constante \\
\hline MSA - 1 & 21,8 & 7,05 & $18,48 \mathrm{BC}$ \\
\hline MSA - 2 & 22,2 & 7,00 & $18,41 \mathrm{C}$ \\
\hline MSA - 3 & 22,7 & 7,03 & $18,26 \mathrm{BC}$ \\
\hline MSA - 4 & 21,7 & 7,01 & $18,05 \mathrm{C}$ \\
\hline MSA - 5 & 21,7 & 7,01 & $18,93 \mathrm{~A}$ \\
\hline C.V. $(\%)$ & ----- & ----- & 0,58 \\
\hline DP & ----- & ----- & 0,11 \\
\hline MSS - 1 & 33,0 & 4,05 & $1,924 \mathrm{BC}$ \\
\hline MSS - 2 & 33,1 & 3,99 & $1,914 \mathrm{C}$ \\
\hline MSS - 3 & 33,1 & 3,99 & $1,921 \mathrm{BC}$ \\
\hline MSS - 4 & 33,0 & 4,00 & $2,014 \mathrm{~A}$ \\
\hline MSS - 5 & 32,7 & 3,99 & $1,944 \mathrm{~B}$ \\
\hline C.V. $(\%)$ & ----- & ----- & 0,57 \\
\hline DP & ----- & ----- & 0,011 \\
\hline MRS - 1 & 22,8 & 2,62 & $0,535 \mathrm{BC}$ \\
\hline MRS - 2 & 22,6 & 2,60 & $0,556 \mathrm{~A}$ \\
\hline MRS - 3 & 22,8 & 2,59 & $0,535 \mathrm{BC}$ \\
\hline MRS - 4 & 24,8 & 2,61 & $0,541 \mathrm{~B}$ \\
\hline MRS - 5 & 23,0 & 2,61 & $0,530 \mathrm{C}$ \\
\hline C.V. $(\%)$ & ----- & ----- & 0,864 \\
\hline DP & ----- & ----- & 0,004 \\
\hline
\end{tabular}

Com relação aos dados das constantes das molas, os resultados mostram a necessidade de ter conhecimento dos valores do comprimento e das constantes das molas dos mecanismos sulcadores (adubo e semente) e recobridores de sementes nos procedimentos de regulagem de uma semeadoraadubadora. Os procedimentos normalmente utilizados pelos técnicos e agricultores levam em consideração que todas as molas tenham comprimento e constantes iguais, fazendo com que a carga aplicada pelas molas nos mecanismos sulcadores ou rompedores de solo não sejam iguais em todas as linhas de semeadura, podendo ser um dos fatores que influenciam na desuniformidade de profundidade de deposição de sementes.

\section{Profundidade do sulco e área de solo mobilizada}

Na Tabela 3, são apresentados os valores médios das variáveis profundidade do sulco e área de solo mobilizada por linha de semeadura. 
TABELA 3. Valores médios da profundidade do sulco para deposição do adubo $(\mathrm{cm})$ e área de solo mobilizada por linha de semeadura $\left(\mathrm{cm}^{2}\right)$.

\begin{tabular}{ccc}
\hline Tratamentos & Profundidade do Sulco $(\mathrm{cm})$ & Área de Solo Mobilizada $\left(\mathrm{cm}^{2}\right)$ \\
\hline T1 & $8,84 \mathrm{~A}$ & $67,90 \mathrm{~A}$ \\
T2 & $6,63 \mathrm{~B}$ & $43,13 \mathrm{~A}$ \\
T3 & $6,52 \mathrm{~B}$ & $52,47 \mathrm{~A}$ \\
T4 & $6,07 \mathrm{~B}$ & $43,48 \mathrm{~A}$ \\
T5 & $5,94 \mathrm{~B}$ & $40,60 \mathrm{~A}$ \\
\hline C.V. $(\%)$ & 8,60 & 37,22 \\
Desvio-Padrão & 0,58 & 18,43 \\
\hline
\end{tabular}

Para a profundidade do sulco, verificou-se que o tratamento T1 diferiu dos demais tratamentos. Nota-se, também, que os tratamentos T2, T3, T4 e T5 foram semelhantes entre si. Isso pode estar associado ao maior número de linhas de semeadura utilizadas nesses tratamentos, garantindo melhor distribuição do peso total da semeadora-adubadora. Quanto à área de solo mobilizada, não se observou diferença entre os tratamentos.

Os valores da área de solo mobilizada são inferiores aos encontrados por SILVA et al. (2001) quando comparou mecanismos sulcadores para plantio direto.

\section{Força requerida na barra de tração} Tabela 4.

Os valores médios da força de tração média e força de tração máxima são apresentados na

TABELA 4. Valores médios da força de tração média $\left(\mathrm{F}_{\mathrm{M}}\right)$ e força de tração máxima $\left(\mathrm{F}_{\mathrm{MÁx}}\right)$.

\begin{tabular}{clc}
\hline Tratamentos & $\mathrm{F}_{\mathrm{M}}(\mathrm{kN})$ & $\mathrm{F}_{\mathrm{MÁX}}(\mathrm{kN})$ \\
\hline T1 & $3,72 \mathrm{~A}$ & $6,10 \mathrm{~A}$ \\
$\mathrm{~T} 2$ & $5,60 \mathrm{~B}$ & $8,75 \mathrm{~B}$ \\
$\mathrm{~T} 3$ & $6,31 \mathrm{C}$ & $8,89 \mathrm{~B}$ \\
$\mathrm{~T} 4$ & $8,08 \mathrm{D}$ & $10,84 \mathrm{C}$ \\
T5 & $8,62 \mathrm{E}$ & $11,12 \mathrm{C}$ \\
\hline C.V. (\%) & 3,13 & 5,11 \\
Desvio-Padrão & 0,20 & 0,47 \\
\hline
\end{tabular}

Com o aumento do número de linhas de semeadura de 1 para 2; 2 para 3; 3 para 4 e de 4 para 5 , o incremento na força de tração média foi 1,$89 ; 0,71 ; 1,77$ e $0,55 \mathrm{kN}$, respectivamente.

Os valores médios da força de tração nos tratamentos T4 $(8,08 \mathrm{kN})$ e T5 $(8,62 \mathrm{kN})$, encontrados neste trabalho, são semelhantes aos encontrados por MAHL et al. (2002) e estão próximos ao obtido por SILVA et al. (2002), que observaram força média de 7,33 kN, para semeadora-adubadora equipada com quatro e seis unidades de semeadura, utilizando mecanismo sulcador do tipo haste sulcadora em sistema de plantio direto.

O requerimento de força de tração máxima na barra (pico) deve-se a irregularidades do terreno, embuchamentos momentâneos ou mesmo devido a diferenças de resistência do solo ao corte. $\mathrm{Na}$ Tabela 4, verifica-se que, para a mesma velocidade de deslocamento, o esforço máximo de tração foi 41,41\% superior ao esforço médio obtido. Nota-se, também, que com o aumento do número de linhas utilizadas há acréscimo significativo da força de tração máxima exigida. Apenas os tratamentos T4 e T5 estão de acordo com os valores obtidos por SILVA (2000), quando avaliou duas semeadorasadubadoras equipadas com quatro linhas para milho. 


\section{CONCLUSÕES}

Não se observou o efeito do número de linhas utilizadas na área de solo mobilizada.

A força de tração média na barra solicitada pela semeadora-adubadora variou em função do número de linhas utilizadas e da disposição das linhas na máquina.

Com o aumento do número de linhas de semeadura de uma para cinco, a força de tração média na barra aumentou em $131,9 \%$.

\section{REFERÊNCIAS}

AMERICAN SOCIETY OF AGRICULTURAL ENGINEERS. Agricultural machinery management. In: _. ASAE standards 1996: Standards Engineering Practices Data. St. Joseph, 1996. p.326-31. (ASAE D496.2 MAR94).

AMERICAN SOCIETY OF AGRICULTURAL ENGINEERS. Agricultural machinery management. In:__ ASAE standards 1999: Standards Engineering Practices Data. St. Joseph, 1999. p.359-66. (ASAE D497.4 JAN98).

ARAÚJO, A.G.; CASÃO JÚNIOR, R.; MEDEIROS, G.B.; CASTRO FILHO, C.; DORETTO, M.; BERTÉ, A.; CAVIGLIONE, J.H.; FIGUEIREDO, P.R.A. Identificação das restrições para expansão do plantio direto na região da represa de Itaipu. In: ENCONTRO LATINO AMERICANO SOBRE PLANTIO DIRETO NA PEQUENA PROPRIEDADE, 3., 1998, Pato Branco. Anais... Pato Branco: Instituto Agronômico do Paraná, 1998. 1 CD-ROM.

ARAÚJO, A.G.; CASÃO JÚNIOR, R.; SIQUEIRA, R. Mecanização do plantio direto: problemas e soluções. Londrina: IAPAR, 2001. 18 p. (Informe da Pesquisa, 137)

EMPRESA BRASILEIRA DE PESQUISA AGROPECUÁRIA. Centro Nacional de Ciência do Solo. Manual de métodos de análise de solos. 2.ed. Rio de Janeiro, 1997. 212 p.

EMPRESA BRASILEIRA DE PESQUISA AGROPECUÁRIA. Centro Nacional de Pesquisa de Solos. Sistema brasileiro de classificação de solos. Rio de Janeiro, 1999. 412 p.

FAGANELLO, A. Avaliação de sulcadores para semeadura.1989. 89 f. Dissertação (Mestrado em Mecanização Agrícola) - Universidade Federal de Santa Maria, Santa Maria, 1989.

MAHL, D.; GAMERO, C.A.; BENEZ, S.H.; SILVA, A.R.B.; SILVA, P.A.; GERMINO, R. Demanda energética de semeadora-adubadora em função da velocidade de semeadura e condição de solo. In: CONGRESSO BRASILEIRO DE ENGENHARIA AGRÍCOLA, 31., 2002, Salvador. Anais... Salvador: Sociedade Brasileira de Engenharia Agrícola, 2002. 1 CD-ROM.

MORRISON JUNIOR, J.E. Interative planter depth control and pneumatic dowpressure system. Transactions of the ASAE, St. Joseph, v.31, p.14-18, 1988.

OLIVEIRA, M.F.B.; SIQUEIRA, R.; RALISCH, R.; ARAÚJO, A.G.; CASÃO JÚNIOR, R. Mobilização do solo por hastes sulcadoras de semeadoras-adubadoras de plantio direto. In: CONGRESSO BRASILEIRO DE ENGENHARIA AGRÍCOLA, 29., 2000, Fortaleza. Anais...

Fortaleza: Sociedade Brasileira de Engenharia Agrícola, 2000. 1 CD-ROM.

SILVA, A.R.B.; BENEZ, S.H.; MAHL, D.; LEITE, M.A.S.; PONTES, J.R.; GRECO, C.R.; MARQUES, J.P.; COSTA, A.M. Avaliação de uma semeadora-adubadora de plantio direto em função de diferentes mecanismos sulcadores e velocidades de deslocamento. In: CONGRESSO BRASILEIRO DE ENGENHARIA AGRÍCOLA, 30., 2001, Foz do Iguaçu. Anais ... Foz do Iguaçu: Sociedade Brasileira de Engenharia Agrícola, 2001. 1 CD-ROM. 
SILVA, P.R.A.; BENEZ, S.H.; MAHL, D.; SILVA, A.R.B.; GERMINO, R. Avaliação da demanda energética de hastes sulcadoras de semeadoras-adubadoras de plantio direto. In: CONGRESSO BRASILEIRO DE ENGENHARIA AGRÍCOLA, 31., 2002, Salvador. Anais... Salvador: Sociedade Brasileira de Engenharia Agrícola, 2002. 1 CD-ROM.

SILVA, S.L. Avaliação de semeadoras para plantio direto: demanda energética, distribuição longitudinal e profundidade de deposição de sementes em diferentes velocidades de deslocamento. 2000. 123 f. Tese (Doutorado em Energia na Agricultura) - Faculdade de Ciências Agronômicas, Universidade Estadual Paulista, Botucatu, 2000. 